\title{
The Acute Single and Mixture Toxicity of Paraquat Dichloride and Deltamethrin to Guppy (Poecillia reticulata)
}

Rully Adi Nugroho ( $\nabla$ rully.nugroho@uksw.edu )

Satya Wacana Christian University: Universitas Kristen Satya Wacana https://orcid.org/0000-00018195-2801

\section{Cornelis van Gestel}

Vrije Universiteit Amsterdam

\section{Research Article}

Keywords: toxicity interactions, equitoxic mixture, antagonism, herbicides, insecticides

Posted Date: June 30th, 2021

DOI: https://doi.org/10.21203/rs.3.rs-665962/v1

License: (c) (i) This work is licensed under a Creative Commons Attribution 4.0 International License.

Read Full License 


\section{Abstract}

Although herbicide and insecticide contamination of surface waters normally occurs in the form of mixtures, the toxicity interactions displayed by such mixtures have only rarely been characterized. This study evaluated the acute effects of single pesticides (paraquat dichloride and deltamethrin, tested in their commercial formulations Gramoxone $276 \mathrm{SL}$ and Decis 25EC) and their equitoxic mixtures on the survival of adult male guppy fish (Poecilia reticulata). Mixture toxicity was evaluated against the reference models of Concentration Addition (CA) and Independent Action (IA). In the single treatments, the $72 \mathrm{~h} \mathrm{LC}_{10}$ and $\mathrm{LC}_{50}$ values were 1.5 and $6.0 \mathrm{mg}$ a.s. $\mathrm{L}^{-1}$ and 0.53 and $3.6 \mu \mathrm{g}$ a.s. $\mathrm{L}^{-1}$ for paraquat dichloride and deltamethrin, respectively. The equitoxic mixtures showed significant paraquat dichloridedeltamethrin antagonism, both based on the CA and the IA model, without significant dose-level dependent deviations.

\section{Introduction}

Aquatic organisms are often exposed to pesticides, mainly from agriculture runoff that may potentially harm non-target organisms (Lushchak et al. 2018). These organisms are usually not exposed to single substances but rather to mixtures of numerous pesticides that vary over-time in concentration and composition (Moustafa et al. 2016). Investigation of single pesticides cannot reflect the true toxicity of their mixtures in the natural environment (Yu et al. 2016). Guppy (Poecilia reticulata) is among the nontarget aquatic organisms exposed to pesticides, especially in tropical countries (Stanley and Preetha 2016).

Among agrochemical products, paraquat dichloride and deltamethrin are still widely used for farming in many developing countries (Lu et al. 2019), including Indonesia. Paraquat, with a half-life in water between 2 to 820 years depending on sunlight and depth of water (Watts 2020), generates the superoxide anion $\left(\mathrm{O}_{2}^{-}\right)$that affects all cellular components (Nandipati and Litvan 2016). Deltamethrin, a type II pyrethroid, with a half-life in water ranging from 2 to 8 weeks (MacLachlan 2002), acts by blocking the sodium channels of nerve filaments lengthening the depolarisation phase and affecting the function of GABA-receptors in nerve filaments (Moid et al. 2012). As a consequence, both pesticides may also affect non-target organisms such as guppy, both single and in mixtures.

Although data are available on the toxicity of most pesticides to a small number of model organisms, limited data exist concerning the mixture toxicity of herbicides and insecticides (Rodney et al. 2013). The toxic effects of paraquat and deltamethrin on tropical planktonic organisms in West Africa have been evaluated by Leboulanger et al. (2009). However, no studies have tested the effect of their mixtures in guppy. Guppy is a commonly used test animal in the bioassay experiments (OECD 1993).

Mixture toxicity is generally predicted using two reference models, Concentration Addition (CA) (Loewe and Muischnek 1929) and Independent Action (IA) (Bliss 1939). Some studies suggest that mixtures of chemicals having the same toxicological modes of action better fit the CA model, while mixtures of 
chemicals having different modes of action tend to be best modelled by IA (Mansano et al. 2017; Queirós et al. 2018). When modes of action of the chemicals are unknown, both CA and IA models are applied and the one that best fits the data is chosen over the other (Pavlaki et al. 2011). However, deviations from these reference models can occur, with synergism or antagonism (S/A) being observed which may also be dose-level dependent (DL) (Jonker et al. 2005).

The aim of this study was to evaluate the acute effects of paraquat dichloride and deltamethrin and their equitoxic mixtures on the survival of the guppy (P. reticulata). For this purpose, toxicity tests were performed with single compounds (tested in their commercial formulations) and their binary combinations, using survival as the endpoint.

\section{Materials And Methods}

$\mathrm{LC}_{10}$ and $\mathrm{LC}_{50}$ values were obtained using the logistic response model after Haanstra et al. (1985), (Eq. 1):

$$
y=\frac{\max }{1+\left(\frac{x}{100-x}\right) *\left(\frac{C_{i}}{L C_{x}}\right)^{\beta}}
$$

where max is the response in the control, ci the concentration of compound $\mathrm{i}, \mathrm{LCx}$ the lethal concentration killing $x \%$ of the rest organisms, and $\beta$ a slope parameter. Values for these parameters and corresponding $95 \%$ confidence intervals were estimated by nonlinear regression in SPSS.

Binary mixtures were then prepared to evaluate the interaction effects on guppy survival, using a more or less equitoxic ratio of paraquat dichloride $\left(0,1.5,3.0,6.0,12.0,24.0 \mathrm{mg}\right.$ a.s. $\left.\mathrm{L}^{-1}\right)$ and deltamethrin $(0,1.5$, $3.0,6.0,12.0,24.0 \mathrm{mg}$ a.s. $\left.\mathrm{L}^{-1}\right)$. The experimental procedure to test the binary pesticide mixtures was identical to the one for the single pesticides. The experimental responses (guppy survival) were compared to the reference CA and IA models to assess the most suitable modelling approach using the MIXTOX tool in Excel developed by Jonker et al. (2005). Deviation functions to the reference models adapted from Jonker et al. (2005), were fitted to the experimental data to identify if synergistic/antagonistic (S/A) as well as dose-level (DL) dependent effects were more suitable to describe the experimental data. These effects can be denoted by the values of two additional model parameters ( $a$ and $b$ ) as detailed in Jonker et al. (2005). Comparisons between different models fitting significantly to the dataset were carried out using the $F$-test under the assumption that a simpler model (i.e. with less parameters) represents a better fitting solution than a more complex one; the rank from the simpler to the most complex is as follows: Baseline $>S / A>D L$.

\section{Results}

In none of the bioassays control mortality occurred, confirming validity of the tests. No chemical analyses were done to confirm exposure concentrations. First, both chemicals were applied in their commercial 
formulations, the formulating agents ensuring homogenous dispersion in the test media and limiting possible loss by sorption to walls of the test containers. Second, due to the short duration of the tests compared to the long half-lives of both chemicals in water (see above), exposure concentrations probably did not decrease much during the tests. Finally, the results of the toxicity tests showed consistent doseresponse curves with effect levels in agreement with values reported in the literature (see below), confirming actual exposure levels were in agreement with the nominal ones.

For both the single pesticides paraquat dichloride and deltamethrin, the toxicity data for effects on guppy survival were reasonably well fitted using the logistic model (Figure 1 ). The $72 \mathrm{~h}$ acute $\mathrm{LC}_{10}$ and $\mathrm{LC}_{50}$ values for the effect of paraquat dichloride and deltamethrin on adult male $P$. reticulata survival were 1.5 and $6.0 \mathrm{mg}$ a.s. $\mathrm{L}^{-1}$ and 0.53 and $3.6 \mu \mathrm{g}$ a.s. $\mathrm{L}^{-1}$, respectively (Table 1 ). The toxic unit (TU) approach, which is commonly used to assess the toxicity of chemical mixtures (Marking 1985), showed that the $72 \mathrm{~h} \mathrm{LC}_{50}$ for the paraquat dichloride+deltamethrin mixture was 1.4 TU (Figure 2 and Table 2). According to the MIXTOX tool this value is significantly higher than the $\mathrm{LC}_{50} \mathrm{~s}$ of $1.0 \mathrm{TU}$ for both paraquat dichloride and deltamethrin, indicating antagonism. Results of the analysis of the effect of the binary mixtures of paraquat dichloride and deltamethrin on the survival of $P$. reticulata using the reference models of CA and IA is shown in Table 3. These results confirm antagonism when tested again the CA model $\left(a=3.61, X^{2}(d f=1)=6.47, P<0.05\right)$ without significant dose-level dependent deviations. The mixture effect was also antagonistic when analyzed using the IA mode $\left(a=3.44, X^{2}(d f=1)=8.16, P<0.05\right)$, also without further deviations.

\section{Discussion}

The $72 \mathrm{~h} \mathrm{LC}_{50}$ values obtained in the present study for the single pesticide exposures are in accordance with the few comparable studies available in the literature. It was found that a $96 \mathrm{~h} \mathrm{LC} \mathrm{L}_{50}$ for the toxicity of paraquat dichloride to $P$. reticulata of $13 \mathrm{mg}$ a.s. $\mathrm{L}^{-1}$ (Eisler 1990). The $72 \mathrm{~h} \mathrm{LC}_{50} \mathrm{~S}$ for the toxicity of deltamethrin to $P$. reticulata ranged between $1.17 \mathrm{mg}$ a.s. $\mathrm{L}^{-1}$ (FAO 2017) and $20.0 \mathrm{mg}$ a.s. $\mathrm{L}^{-1}$ (Stalin et al. 2008). All these studies show that deltamethrin is highly toxic, with $96 \mathrm{hC}_{50}$ s for fish and other aquatic organisms being $<10 \mathrm{mg}$ a.s. $\mathrm{L}^{-1}$ (Amin and Hashem 2012; Ceyhun et al. 2010). The differential modes of action and lipophilic properties of the two pesticides likely explain for the difference in toxicity to guppy. Deltamethrin is highly lipophilic compared to paraquat dichloride, which facilitates a high absorption by the gills of fish even at very low concentrations in the water (Amin and Hashem 2012; Oliveira et al. 2018).

This study showed overall and significant paraquat dichloride-deltamethrin antagonistic deviations from the CA and IA models, without significant dose-level dependent deviations. Antagonism occurs when pesticides interfere with each other's effect (Hernández et al. 2013). The results is a reduction in the effect predicted from the toxicity of the individual compounds which do not need to be structurally similar (Zelinger 2011). Although no previous studies were found on the effects of mixtures of paraquat dichloride and deltamethrin on the survival of guppy for a more direct discussion, antagonistic effects of 
pesticide mixtures are not rare. Previous studies showed a significant antagonistic effect of the binary mixtures of deltamethrin and organophosphates for different organisms (Singh et al. 2020; Toumi et al. 2018).

There is little evidence of paraquat dichloride and deltamethrin interactions in the literature. Thus, it is unlikely that a paraquat dichloride-deltamethrin complex may be formed which is less biologically active in the guppies than paraquat dichloride or deltamethrin alone. Two possible mechanisms may contribute to or cause the observed antagonism. First, antagonism may be due to one chemical stimulating the metabolism of the second one or somehow interfering with its absorption. Fishes are known to react to chemical stressors by up-regulating numerous detoxifying enzymes such as cytochrome P450, phase II conjugation enzymes and anti-oxidative enzymes (Ayanda et al. 2015). It was shown that the transcriptional levels of cytochrome P450, export pump gene MDR1 (multi-drug resistance gene), and erythromycin-N-demethylase activity were generally up-regulated by paraquat exposure (Ma et al. 2018). On the other hand, cytochrome $P 450$ played an important role in deltamethrin detoxification (Elzaki et al. 2018). These findings indicate that these genes or enzymes are potentially involved in the detoxification of not only paraquat dichloride but also deltamethrin in the guppy consequently contributing to antagonism of their mixture.

Moreover, it has been postulated that $\mathrm{NAD}(\mathrm{P}) \mathrm{H}$-dependent diaphorases are responsible for the in vivo reduction of paraquat to the paraquat mono cation-free radical, which is then rapidly re-oxidized (returning to its original form) in the presence of $\mathrm{O}_{2}$ with subsequent generation of superoxide anion radicals and other reactive oxygen species that are responsible for paraquat toxicity (Dinis-Oliveira et al. 2008). On the other hand, the silencing or inhibition of quinone oxidoreductase, a NAD(P)H-independent flavoenzyme, significantly attenuates paraquat toxicity in vitro and strongly antagonizes paraquatinduced systemic toxicity and animal mortality (Janda et al. 2013). It is plausible to speculate that the antagonistic interaction found in the present study is probably also due to the inhibition of quinone oxidoreductase by deltamethrin. However, there is is no information whether guppies have quinone oxidoreductase, while the presence of this enzyme was confirmed for zebrafish, puffer fish and ray-finned fish (Vasiliou et al. 2006).

Second, a number of researchers found that reactive oxygen species can participate in various physiological processes, including the induction of autophagy that is considered to be an effective defence mechanism against cellular stress (Scherz-Shouval and Elazar 2011). Autophagy enhacement was neuroprotective against deltamethrin-induced apoptotic cell death (Park et al. 2017). Since paraquat dichloride induces apoptosis and autophagy (Park et al. 2013), it is suggested that paraquat dichloride protects against deltamethrin-induced apoptosis by enhancing autophagy. However, all of these suggestions need to be further clarified.

As the population is exposed to multiple pesticides (either simultaneously or sequentially) through the diet and the environment, the impact of pesticide mixtures on animal health represents a challenge for risk assessment. An added difficulty is that the number and composition of potential pesticide mixtures is 
often unknown and changes over time, and the precise mechanism of toxicity of many pesticides is still unknown (Hernández et al. 2017).

This study showed that deltamethrin is much more toxic for guppies than paraquat dichloride. Mixture toxicity of these pesticides showed overall and significant paraquat dichloride-deltamethrin antagonistic deviations from both the concentration addition (CA) and the independent action (IA) models, without significant dose-level dependent deviations. Where the antagonistic deviation from CA could be due to the fact that the chemicals have a different mode of action, antagonism against the IA model suggests that other interactions are involved that lead to a reduced toxicity of these pesticides when present as a mixture.

\section{References}

Amin KA, Hashem KS (2012) Deltamethrin-induced oxidative stress and biochemical changes in tissues and blood of catfish (Clarias gariepinus): Antioxidant defense and role of alpha-tocopherol. BMC Vet Res 8:45-52.

Ayanda Ol, Oniye SJ, Auta J, Ajibola VO (2015) Acute toxicity of glyphosate and paraquat to the african catfish (Clarias gariepinus, Teugels 1986) using some biochemical indicators. Trop Zool 28:152-162.

Bliss $\mathrm{Cl}$ (1939) The toxicity of poisons applied jointly. Ann Appl Biol 26:585-615.

Ceyhun SB, Șentürk M, Ekinci D, Erdorğan O, Çiltaş A, Kocaman EM (2010) Deltamethrin attenuates antioxidant defense system and induces the expression of heat shot protein 70 in rainbow trout. Comp Biochem Physiol C 152:215-223.

Dinis-Oliveira RJ, Duarte JA, Sánchez-Navarro A, Remião F, Bastos ML, Carvalho F (2008) Paraquat poisonings: Mechanisms of lung toxicity, clinical features, and treatment. Crit Rev Toxicol 38:13-71.

Eisler R (1990) Paraquat hazards to fish, wildlife, and invertebrates: A synoptic review. Biological Report 85:(1.22). https://www.pwrc.usgs.gov/eisler/CHR_22_Paraquat.pdf. Accessed December 22, 2020.

Elzaki MEA, Miah MA, Peng Y, Zhang H, Jiang L, Han Z (2018) Deltamethrin is metabolized by CYP6FU1, a cytochrome P450 associated with pyrethroid resistance, in Laodelphax striatellus. Pest Manag Sci 74:1265-1271.

FAO (2017) FAO Specifications and evaluation for agricultural pesticides: Deltamethrin. Rome: Food and Agricultural Organization, Rome.

Haanstra L, Doelman P, Voshaar JHO (1985) The use of sigmoidal dose-response curves in soil ecotoxicological research. Plant Soil 84:293-297.

Hernández AF, Gil F, Lacasaña M (2017) Toxicological interactions of pesticide mixture: An update. Arch Toxicol 91:3211-3223. 
Hernández AF, Parrón T, Tsatsakis AM, Requena M, Alarcón R, López-Guarnido 0 (2013) Toxic effects of pesticide mixtures at a molecular level: Their relevance to human health. Toxicol 307:136-145.

Janda E, Parafati M, Aprigliano S, Carresi C, Visalli V, Sacco I, Ventrice D, Mega T, Vadalá N, Rinaldi S, Musolino V, Palma E, Gratteri S, Rotiroti D, Mollace V (2013) The antidote effect of quinone oxireductase 2 inhibitor against paraquat-induced toxicity in vitro and in vivo. Br J Pharmacol 168:46-59.

Jonker MJ, Svendsen C, Bedaux JJM, Bongers M, Kamenga JE (2005) Significance testing of synergistic/antagonistic, dose level-dependent, or dose ratio-dependent effects in mixture dose-response analysis. Environ Toxicol Chem 24:2701-2713.

Leboulanger C, Bouvy M, Pagano M, Dufour RA, Got P, Cecchi P (2009) Responses of planktonic microorganisms from tropical reservoirs to paraquat and deltamethrin exposure. Arch Environ Contam Toxicol 56:39-51.

Loewe S, Muischnek H (1929) Combinated effects I announcement-implements to the problem. Archiv Exper Pathol u Pharmakol 114:313-326.

Lu Q, Sun Y, Ares I, Anadón A, Martínez M, Martínez-Larrañaga M-R, Yuan Z, Wang X, Martínez MA (2019) Deltamethrin toxicity: A review of oxidative stress and metabolism. Environ Res 170:260-281.

Lushchak VI, Matviishyn TM, Husak VV, Storey JM, Storey KB (2018) Pesticide toxicity: A mechanistic approach. EXCLI J. 17:1101-1137.

Ma J, Li Y, Li W, Li X (2018) Hepatotoxicity of paraquat on common carp (Cyprinus carpio L.). Sci Total Environ 616-617:889-898.

MacLachlan D (2002) Deltamethrin, in: Banasiak U, Caldas D, Funk S, Hamilton DJ, Hill A, MacLachlan D, Ossendorp B, Yamada Y (Eds.) Pesticide residues in food: Evaluations Part I Residues. FAO Plant Production and Protection Paper 172:167-358.

Mansano AS, Moreira RA, Dornfeld HC, Freitas EC, Viera EM, Sarmento H, Rocha O, Selegrim MHR (2017) Effects of diuron and carbofuran and their mixtures on the microalgae Raphidocelis subcapitata. Ecotoxicol Environ Saf 142:312-321.

Marking LL (1985) Toxicity of chemical mixtures. In: Rand GM, Petrocelli SR, eds. Fundamentals of aquatic toxicology: Methods and applications. Hemisphere Pub. Corp., Washington DC, pp. 1985:164176.

Moid N, Patel F, Shrimali A, Desai KR, Highland HN (2012) Toxicological implications of Type II pyrethroides, deltamethrin on certain tissue of swiss albino male mice. Int J Pharma Res Health Sci 5:4154. 
Moustafa GG, Shaaban FE, Hadeed AHA, Elhady WM (2016) Immunotoxicological, biochemical, and histopathological studies on Roundup and Stomp herbicides in Nile catfish (Clarias gariepinus). Vet World 9:638-647.

Nandipati S, Litvan I (2016) Environmental exposures and Parkinson's disease. Int J Environ Res Public Health 13:881.

OECD (1993) OECD guidelines for testing of chemicals. Organization for Economic Cooperation and Development, Paris.

Oliveira JM, Losano NF, Condessa SS, de Freitas RMP, Cardoso SA, Freitas MB, de Oliveira LL (2018) Exposure to deltamethrin induces oxidative stress and decreased of energy reserve in tissues of the Neotropical fruit-eating bat Artibeus lituratus. Ecotoxicol Environ Saf 148:684-692.

Park JH, Lee JE, Shin IC, Koh HC (2013) Autophagy regulates chlorpyrifos-induced apoptosis in SH-SY5Y cells. Toxicol App Pharmacol 268:55-67.

Park YS, Park JH, Ko J, Shin IC, Koh HC (2017) mTOR inhibition by rapamycin protects against deltamethrin-induced apoptosis in PC12 cells. Environ Toxicol 32:109-121.

Pavlaki MD, Pereira R, Loureiro S, Soares AMVM (2011) Effects of binary mixtures on the life traits on Daphnia magna. Ecotoxicol Environ Saf 74:99-110.

Queirós L, Vidal T, Nogueira AJA, Gonçalves FJM, Pereira JL (2018) Mixture toxicity assisting the design of eco-friendlier plant protection products: A case-study using a commercial herbicide combining nicosulfuron and terbuthylazine. Sci Rep 8:5547.

Rodney SI, Teed RS, Moore DRJ (2013) Estimating the toxicity of pesticide mixtures to aquatic organisms: A review. Hum Ecol Risk Assess 19:1557-1575.

Scherz-Shouval R, Elazar Z (2011) Regulation of autophagy by ROS: Physiology and pathology. Trends in Biochem Sci 36:30-38.

Singh S, Tiwari RK, Pandey RS (2020) An insight into the impact of triazophos and deltamethrin pesticides as individual and in combination on oxidative stress and histopathological alterations in Eudrilus eugeniae. Chem Ecol 36:155-173.

Stalin SI, Kiruba S, Das SSM (2008) A comparative study on the toxicity of a synthetic pyrethroid, deltamethrin and a neem based pesticide, azadirachtin to Poecilia reticulata Peters 1859 (Cyprinodontiformes: Poeciliidae). Turk J Fish Aquat Sci 8:1-5.

Stanley J, Preetha G (2016) Pesticide toxicity to non-target organisms: Exposure, toxicity and risk assessment methodologies. Springer Nature, Dordrecht. 
Toumi H, Boumaiza M, Millet M, Radetski CM, Camara BI, Vincent F, Masfaraud J-F, Férard JF (2018) Combined acute ecotoxicity of malathion and deltamethrin to Daphnia magna (Crustacea, Cladocera): Comparison of different data analysis approaches. Environ Sci Pollut Res Int 25:17781-17788.

Vasiliou V, Ross D, Nebert DW (2006) Update of the NAD(P)H:quinone oxidoreductase (NQO) gene family. Hum Genomics 2:329-335.

Watts M (2020) Paraquat; 2011. http://wssroc.agron.ntu.edu.tw/note/Paraquat.pdf. Accessed on December 22, 2020.

Yu RX, Wang YH, Hu XQ, Wu SG, Cai LM, Zhao XP (2016) Individual and joint acute toxicities of selected insecticides against Bombyx mori (Lepidoptera: Bombycidae). J Economic Entomol 109:327-333.

Zelinger HI (2011) Human toxicology of chemical mixtures: Toxic consequences beyond the impact of one-component product and environmental exposures, 2nd ed. Elsevier, Oxford.

\section{Tables}

Table 1. Dose-response curve parameters for the effect of paraquat and deltamethrin on the survival of Poecilia reticulata after $72 \mathrm{~h}$ exposure. Shown are the Max and slope $(\beta)$ with SE and the $L C_{x}$ values with $95 \%$ confidence intervals derived by fitting a logistic dose-response model to the data (see Figure 1 ).

\begin{tabular}{lllll}
\hline \multirow{2}{*}{ Exposure } & \multicolumn{2}{l}{ Parameter } & \multirow{2}{*}{$R^{2}$} \\
\cline { 2 - 4 } & Max & $\beta$ & $L C_{x}\left(\mathrm{mg} \mathrm{L}^{-1}\right)$ & 0.732 \\
\hline Paraquat & 4.0 & 1.6 & $L C_{10}=1.5[-0.48-3.5] ;$ & \\
dichloride & $(0.40)$ & $(0.58)$ & $L C_{50}=6.0[2.9-9.1]$ & 0.919 \\
Deltamethrin & 4.0 & 1.2 & $L C_{10}=0.00053[0.000057-0.0010] ;$ & \\
& $(0.22)$ & $(0.20)$ & $L C_{50}=0.0036[0.0024-0.0048]$ & \\
\hline
\end{tabular}

Table 2. Dose-response curve parameters for the effect of paraquat and deltamethrin and their mixture on the survival of Poecilia reticulata after $72 \mathrm{~h}$ exposure. Effect parameters are based on toxic units (TUs) of the pesticides, which are derived by dividing exposure concentrations by the respective $\mathrm{LC}_{50} \mathrm{~S}$ of the individual pesticides. Shown are the Max and slope $(\beta)$ with SE and the $L C_{x}$ values with $95 \%$ confidence intervals derived by fitting a logistic dose-response model to the data (see Figure 2). 


\begin{tabular}{lllll}
\hline \multirow{2}{*}{ Exposure } & \multicolumn{2}{l}{ Parameter } & \multirow{2}{*}{$R^{2}$} \\
\cline { 2 - 4 } & $M a x$ & $\beta$ & $L C_{x}(\mathrm{TU})$ & 0.732 \\
\hline Paraquat & 4.0 & 1.6 & $L C_{10}=0.26[-0.08-0.59] ;$ & \\
dichloride & $(0.40)$ & $(0.58)$ & $L C_{50}=1.0[0.48-1.52]$ & 0.919 \\
Deltamethrin & 4.0 & 1.2 & $L C_{10}=0.15[0.016-0.28] ;$ & \\
& $(0.22)$ & $(0.20)$ & $L C_{50}=1.0[0.66-1.34]$ & 0.934 \\
Mixture & 4.0 & 1.1 & $L C_{10}=0.18[0.026-0.34] ;$ & \\
& $(0.22)$ & $(0.17)$ & $L C_{50}=1.4[0.90-1.8]$ & \\
\hline
\end{tabular}

Tabel 3. Effect of a binary mixture of paraquat dichloride and deltamethrin on the survival of Poecilia reticulata exposed for $72 \mathrm{~h}$. Values are calculated based on the concentration addition model (CA) and the independent action model (IA) extended with deviation parameter a showing synergism/antagonism $(S / A)$ and an additional deviation parameter $b$ for dose level-dependent deviations (DL). The $p\left(\chi^{2}\right)$ values indicate the significance of the additional deviation parameters. Values printed in bold indicate the best model fit and were used for drawing conclusion on the toxicity of mixture.

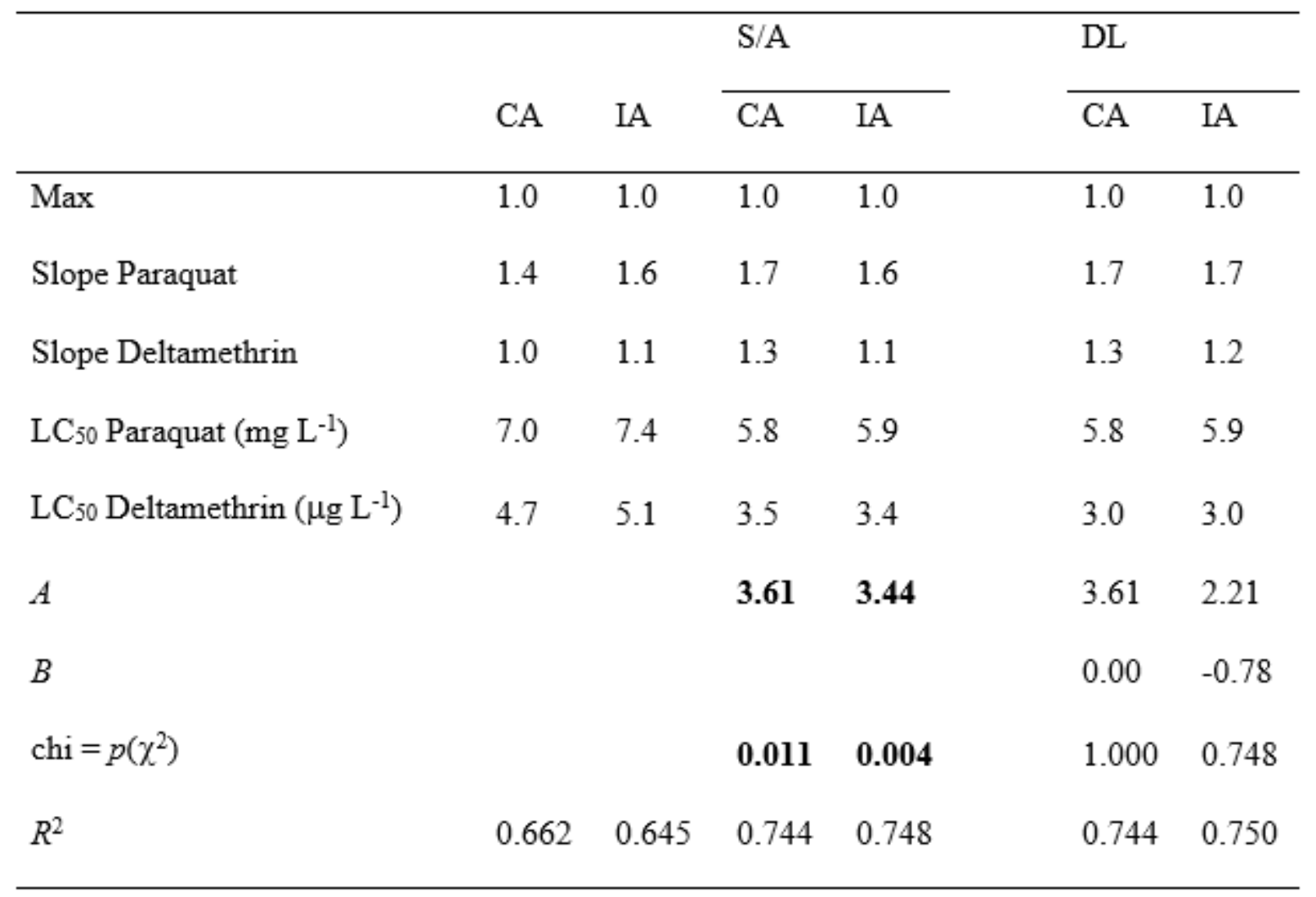



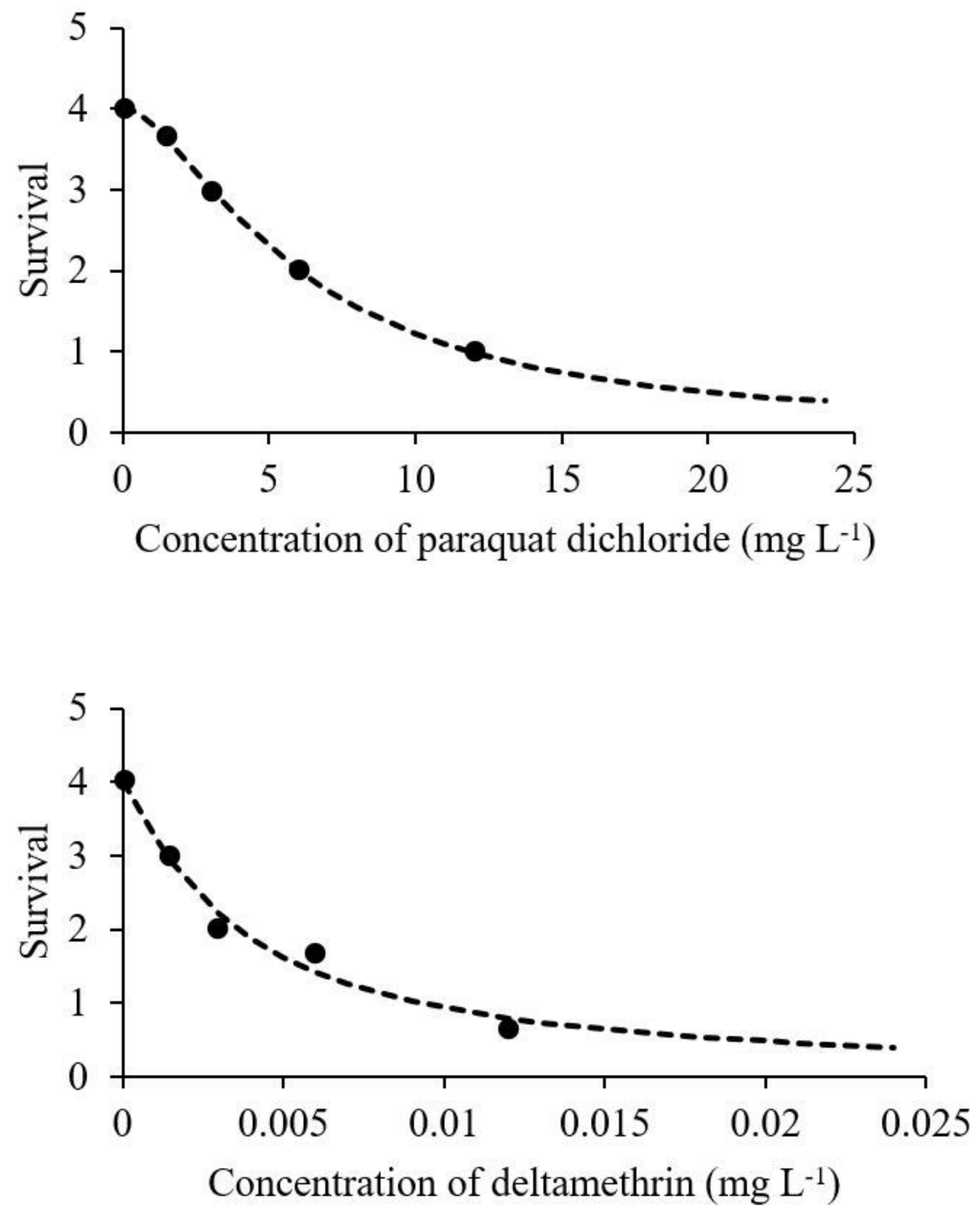

Figure 1

Effects of single paraquat dichloride and deltamethrin on the survival of Poecilia reticulata after $72 \mathrm{~h}$ exposure. Lines show the fit to the data of a logistic dose-response model. See Table 1 for the LC10 and LC50 values calculated from the dose-response curves. 


\section{----- Paraquat dichloride ......... Deltamethrin - Mixture}

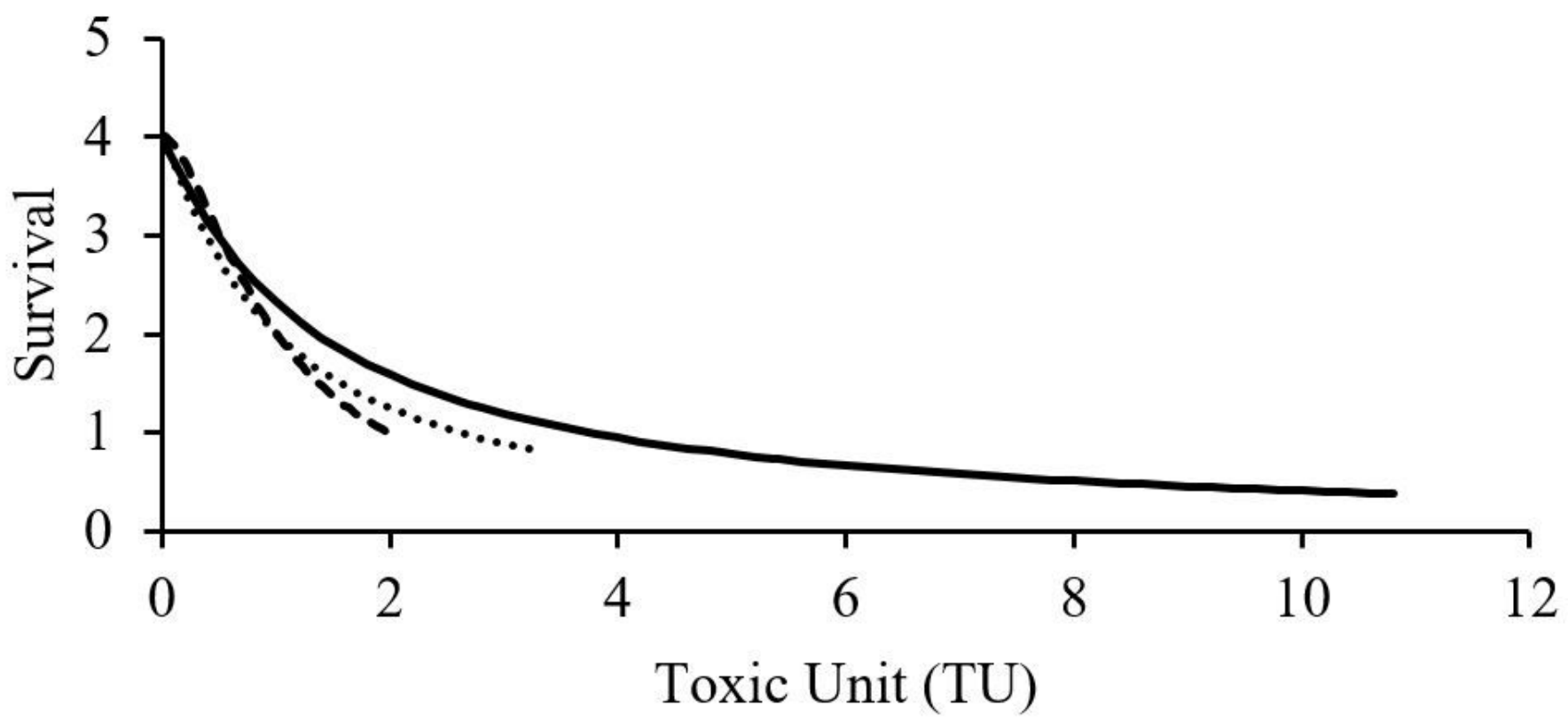

Figure 2

Dose-response relationships for the effects of paraquat dichloride, deltamethrin, and their mixture on the survival of Poecilia reticulata after $72 \mathrm{~h}$ exposure. Concentrations are expressed as Toxic units, by dividing the exposure concentration of each chemical by its LC50 for effects on guppy survival. Lines show the fit to the data of a logistic dose-response model. See Table 2 for the LC10 and LC50 values calculated from the dose-response curves.

\section{Supplementary Files}

This is a list of supplementary files associated with this preprint. Click to download.

- Declarations.docx 